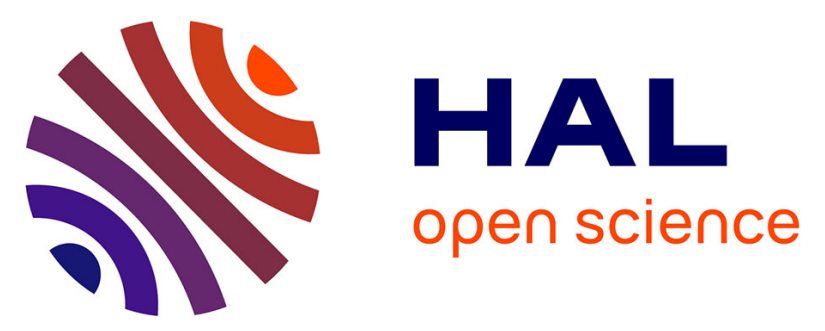

\title{
Improving Agricultural Information and Knowledge Transfer in Cambodia - Adopting Chinese Experience in Using Mobile Internet Technologies
}

Yanan Hu, Yun Zhang, Yanqing Duan

\section{- To cite this version:}

Yanan Hu, Yun Zhang, Yanqing Duan. Improving Agricultural Information and Knowledge Transfer in Cambodia - Adopting Chinese Experience in Using Mobile Internet Technologies. 9th International Conference on Computer and Computing Technologies in Agriculture (CCTA), Sep 2015, Beijing, China. pp.357-368, 10.1007/978-3-319-48354-2_36 . hal-01614193

\section{HAL Id: hal-01614193 \\ https://hal.inria.fr/hal-01614193}

Submitted on 10 Oct 2017

HAL is a multi-disciplinary open access archive for the deposit and dissemination of scientific research documents, whether they are published or not. The documents may come from teaching and research institutions in France or abroad, or from public or private research centers.
L'archive ouverte pluridisciplinaire HAL, est destinée au dépôt et à la diffusion de documents scientifiques de niveau recherche, publiés ou non, émanant des établissements d'enseignement et de recherche français ou étrangers, des laboratoires publics ou privés.

\section{(c)(1)}

Distributed under a Creative Commons Attribution| 4.0 International License 


\title{
Improving Agricultural Information and Knowledge Transfer in Cambodia - Adopting Chinese Experience in using Mobile Internet Technologies
}

\author{
Yanan $\mathrm{Hu}$, Yun Zhang, Yanqing Duan* \\ Foreign Economic Cooperation Centre, Ministry of Agriculture, Beijing, China \\ zhangyun@agri.gov.cn; huyanan05@hotmail.com \\ Yanqing Duan \\ Business and Information Systems Research Centre, University of Bedfordshire, Luton, UK \\ yanqing.duan@beds.ac.uk
}

\begin{abstract}
Agriculture is a knowledge intensive sector. Information and knowledge plays an essential role in helping farmers to improve productivity and sustainabilitythroughpromoting and adopting the most effective and relevant innovations and technologies. With rapid development and advances in agriculturalscience and technology, traditional agriculture practices have been transformed to knowledge based and digital agriculture production. This paper reports a project that aims to improve the agricultural information and knowledge flow in Cambodia by adopting China's success in using Mobile Internet Technologies. The paper providesa brief reviewof China's current achievements in using ICTs to accelerate information and knowledge flow in Agriculture and Cambodia's current status in using ICT for agriculture information disseminations. An empirical investigation was carried out in Cambodia to gain more insights into the farmers information needs and their intention to adopt Mobile Internet based information dissemination services. Based on the empirical study, Chinese experience in using Mobile App was introduced and a mobile App called AgriAppwas designed and tailored to meet the Cambodia's needs and conditions. This AgriApp was initially tested and valuable feedback was collected for improvement and better deployment in Cambodia.
\end{abstract}

\section{Introduction}

The agriculture sector in Cambodia is the most important source of income. Cambodia's economy is still highly dependent on agriculture, which contributes close to one-third of national GDP and employs more than half of the total labour force (Yu and Diao 2011). However, as a result of the rapidly changing socio-economic conditions since 1990, Cambodia agriculture sector faces many new challenges such as high population growth, embracing a market economy, nationwide food security and decreasing agricultural production conditions. These challenges are exacerbated by the limited access to agricultural knowledge and information in the rural areas. There are limited knowledge bases and appropriate approaches for information and knowledge transfer. As a result, the latest agricultural technology and market information cannot reach farmers in a timely manner. At the same time, farmers' problems and inquires cannot be addressed directly and timely. 
Therefore, it is imperative to improve Cambodia's agricultural productivity and economic situation of farmers through better information dissemination service.

Over the last three decades, China has been very successful in transforming its Agriculture sector through the effective deployment of Information and Communication Technologies (ICTs). Information processing and dissemination have played a critical role in this transformation process (Zhang, et al, 2015). It is believed that sharing Chinese experience and best practice would help Cambodian's agriculture sector in utilising the latest ICTs to facilitate knowledge and information dissemination. This paper reports a research project that seeks to extract useful and practical Chinese experience, especially in the area of the applications of the latest mobile Internet and GIS technologies, and adapt it to the Cambodian context. The research focuses on analysing information needs, selecting information sources, developing knowledge and information repository, and designing and demonstrating technical tools and platforms for effective information dissemination. Theresearch project combines Chinese technologies for information sharing using smart phones with Cambodian data to promote effective and efficient agricultural information dissemination, so as to improve the knowledge and information dissemination flow in the rural area of Cambodia in the long run.

\section{Review of agricultural information dissemination in China}

This research reviews the current ICT-based information service models in China to develop a better understanding on how different ICT-based information service models are designed and adopted in China; and to share the knowledge and experience in applying emerging ICTs in disseminating agriculture information to farmers to improve productivity and economic, social and environmental sustainability.

Information services for farmers at the national and regional level are a promising new field of research and application in the emerging field of e-agriculture (Gakuru, et al 2009). Information services play a critical role in modern agriculture and rural development and Information management and accessibility are at the core for information dissemination $(\mathrm{Li}$, 2011).To improve agriculture productivity, farmers have an ever increasing demand for information because accessing information and knowledge is essential for improving their productivity (Zhang, et al 2015).Agricultural information can be effectively disseminated by television, radio, newspapers, Internet, mobile phone,Short Message Service (SMS), Mobile Internet APPs (3G, 4G smart phones and handhelds) orthecombinations of different channels.

With the development of information technology, the agriculture information service model is constantly evolved and improved. Based on extensive review of reports and literature (e.g. Li, 2009 and 2011;Liu, 2010; MOA Information Centre, 2014), the agricultural information service models in China are classified into the following types:

1. Web Portal - a collection of relevant web sites to form an one stop center for users, e.g. MOA Web Portal, etc.

2. Voice-Based Service - information dissemination through telephone, i.e. call centers, e.g. Liaoning 12316 Golden Farming Hotline.

3. Text (SMS)-Based Service - information dissemination through text message of mobile phones. This service is normally jointly operated by Agriculture sector and Telecom service providers, e.g Hunan Agri-Telecom Platform.

4. Self-Support Online Community - information services provided by a community to 
its members. This is a membership based system involving all stakeholders, members share experience and exchange information through interactive service platforms, e.g. farmers Mailbox in Zhejiang Province.

5. Interactive Video Conferencing Service - using online multimedia technology to facilitate information service, e.g Shanghai Farmers "One Click and Go" service, or Intelligent Farmers service.

6. Mobile Internet Based Service - information dissemination through smart phone service, e.g. Agribusiness price information, E-news, etc.

7. Unified Multi-Channel Service Model - utilizing multiple methods to effectively disseminate information through telephones, computers, and mobile phones., e.g "3 in 1" service in Fujian

To select the most appropriate models, the information infrastructure, the operating costs, farmers' capabilities, farmers' information consumption behaviour and, most importantly, the local context should be taken into consideration (Zhang, 2012).

The key impact of agriculture information services in China can be highlighted in the following areas (Zhang, et al 2015):

- Improved the efficiency of Agriculture Services, e.g. "12316 hotline", "Unified 3 in 1 service", etc.

- Increased farmers' income

- Improved agriculture productivity

- Reduced the digital gap between rural areas and modern cities

\section{Agricultural Information Dissemination in Cambodia}

Agricultural sector plays a very important role in economic development of Cambodia. Hence, the Royal Government of Cambodia (RGC) has made a strong commitment to improve the country's agriculture sector after successfully leading the Cambodian economy out of the most difficult time of recent global financial crisis and economic downturn (CARDI, 2014). However, Cambodia is currently in urgent needs for developing adequate agricultural information dissemination services. For example, although effective market information systems in Cambodia can reduce information asymmetries, increase competitiveness, and improve marketing system efficiencies (EC-FAO, 2015), majority of farmers are still have no access the market information in a timely way. There is, therefore, strong demand for higher efficiency and effectiveness in agricultural information dissemination within Cambodian farming communities.

The Cambodian government has realised the importance of collecting, processing, managing and disseminating agricultural information and developed a series of initiatives to improve the situation.For example, Council of Agriculture and Rural Development (CARD) has established a single entry-point called the 'Cambodian Agricultural and Rural Development information Gateway' (CARDiG). The aim of CARDiG is to provide a portal for information sharing on agriculture and rural development and boost information and knowledge management among stakeholders through better access to web-based information.

Under the supervision of Ministry of Agriculture, Forestry and Fisheries (MAFF), ICT is widely used in government organisations at all levels to enhance the information flow to 
farmers and other stakeholders. MAFF has been implementing some projects working on improving productivity and market information of agricultural, such as providing all related information through radio broadcasting program, mobile SMS and websites. Besides that, MAFF has also formed many agricultural cooperatives at the rural community level and equip those communities with a set of desktop computer and other agricultural lessons CD.

Cambodian Agricultural Research and Development Institute (CARDI) has set up an agriculture-related electronic library, which includes various agricultural publications and research bulletins for online reading and download. Cambodia has also developed databases on agricultural subjects, such as soil, phytopathology and rice planting. Agricultural information is usually disseminated via radio, TV, mobile SMS and websites, providing effective guidance for agricultural production.

In summary, the main methods used in disseminating the agricultural information in Cambodia are shown in figure 1 (CARDI, 2014) which include:

Traditional face to face approaches - This approach disseminates information to farmers through field visit and demonstration, farmers field school and training, Agriculture forum, annual conference, monthly meetings, etc. This has been the most popular approach by farmers, but it is not the most effective and efficient method due to the financial and human resources involved.

Printed materials - Scientific and technical information was delivered to stakeholders through the periodical publication of research note, research bulletin, farmers' notes, project report, Journal of agriculture and other reading materials.

Mass media (TV and radio) - Information is broadcasted to a large number of farmers at fix times. The survey and focus group feedback indicate that this was seen as a not very popular methods because of the inflexibility of fix programmes.

Internet and CD - CARDI and other relevant bodies also publish regular information and demonstration of new development in their website for key stakeholder, such as: agricultural extension agents and key farmers to obtain the latest news and development in agriculture sector. CDs are also produced and distributed to farmers and agents for information dissemination purposes.

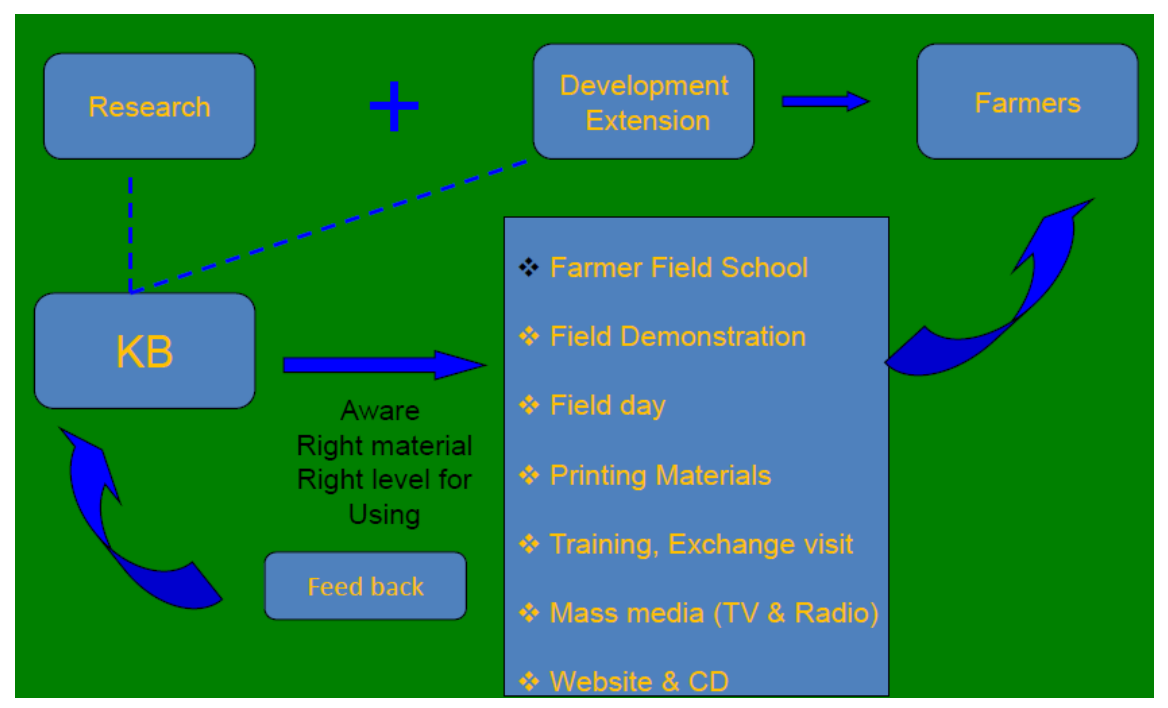


Figure 1. Cambodia agricultural information dissemination methods (CARDI, 2014)

Though Network technology is relatively backward with low coverage, it is a fast growing area. Mobile phone penetration is significantly higher than landline. Currently, a total of 21 companies have the business license from Ministry of Posts and Telecommunications. There are eight mobile phone companies, two un-mobile phone companies, twenty eight network service companies, seven 3G service companies, 15 VOIP service companies and 16 VSAT service companies. It is predicated that Cambodian mobile phone users will up to 20 million, and mobile phone will become a communication tool widely used in daily life and work. In Cambodia, about 2.5 million people use Internet, accounting for $17.5 \%$ of the total population, so Cambodia has the policy environment, hardware and software to build the agricultural information service platform.

However, the review of current situation suggests that although Cambodia government have realised the importance and needs for improving agricultural information dissemination and developed a series initiative in recent year, there is still a huge gap for significant improvement. The current information dissemination patterns in Cambodia are all one-way communication and lack of interactivity. They often cannot solve the specific problems of farmers in a timely and effective way. The agricultural information technology infrastructure in Cambodia is quite dated. Information dissemination mainly uses traditional media, such as radio, television, and paper based publications, so the dissemination efficiency and coverage are greatly restricted. The latest agricultural policy from agricultural sector is mainly released top down in the form of telephone. The way to promote the agricultural technology is regularly to organize trainings for farmers, so only a few farmers can get the information, and the effectiveness and pertinence is poor. For example, majority of farmers still have little information and difficult to obtain timely and accurate market and buyer information, leading to agricultural products unmarketable or the sale price is much lower than average. Aimed at these problems above, Cambodia hopes to push the latest agricultural technology to farmers through the advanced mobile Internet technology and the GMS agriculture network platform.

In China, with the development of information technology, the agriculture information service models and operating patterns are constantly developed and enhanced. It is believed that Cambodia can benefit greatly from the Chinese experience and best practice if introduced and adapted effectively.

\section{Understanding the information needs of Cambodia farmers -empirical investigations}

To introduce China's success experience in agricultural information services and meet Cambodia farmers' needs and conditions, this research conducted a number of empirical investigations in Cambodia including surveys, focus groups and interviews with different stakeholders. The findings of the investigations help to gain in-depth insights into farmers' accessibility to information resources, their information needs and seeking behaviour, their intention of adopting ICT-based dissemination models, etc. The key findings also help to select the most suitable solutions for adapting Chinese information dissemination experiences using Mobile Internet technology. 


\subsection{Farmer survey on information dissemination and adoption intention of mobile device}

A questionnaire of farmer survey was developed and translated into Khmer. It consisted of two main parts which were current situation and adoption intention questions. The part one of the survey covered the following areas:

1) Date and location of survey

2) Personal information

3) Farm information

4) What are the main problems in the current information dissemination?

5) Whom do you want to receive the information from?

6) How important do you believe to receive the following types of information to improve your farm productivity

7) Your preferred information delivery methods

Part two of the survey concerned the adoption intention that collect farmers perceptions and intentions in the following areas:

1) Performance expectancy

2) Effort expectancy

3) Attitude toward using technology

4) Social influence

5) Facilitating conditions

6) Behavioural intention to use the system if the system is available

The farmer survey was conducted in the two target pilot locations and a total of 95questionnaires were collected. During the surveys, group discussions and interviews with farmers, farmer managers and key farmers were also conducted to explore further their information dissemination needs and preferred dissemination channels.

At the end of farmers' surveys, some of participants expressed their appreciation saying that they were very pleased to be invited and the information and demonstration were very useful for them. It was an eye-opening experience for them.

The survey results indicate that the major problems are no necessary equipment to access the electronic information, having difficulties to find the information they need, notknowing where to find information, and no relevant information available. Farmers would like to receive all relevant information that can help them improve productivity and sell their products. The adoption intention is also high although most of farmers still don't have smart phones.

\subsection{Workshop on upgrading Cambodian's agricultural information dissemination system}

A workshop on upgrading Cambodian's Agricultural Information Dissemination System was conducted in Phnom Penh to share experiences regarding to agricultural information dissemination system in Cambodia and the successful experiences of ICT technologies, especially mobile internet technology in China. The outcomes of the workshop were also 
contributing to guide the project implementation. A total of 30 participants from different institutions andorganizations attended the workshop.

After introducing the Chinese current success in agricultural information dissemination using ICTs, the participants were divided into three groups to discuss: 1- Problem and challenge of ICT in Cambodia, 2 - Adoption of ICT based information dissemination technology in Cambodia, and 3 - What is the most needed information for farmers?.

The outcome of group discussions are summarised below:

The problems and challenges of ICT based information dissemination in Cambodia:

1. Most farmers lack of knowledge in utilization of internet

2. Extension documents are not widely used

3. Not availability of internet in the rural areas

4. Not accessibility electricity in remote areas

5. Insufficient IT equipment for accessing the Internet, e.g. PC, smart phones or tablets

6. Financial problem: the rural people couldn't afford to purchase computers or phones

7. Internet service charges are too costly

8. Low literacy level

9. Market information is not regularly and widely disseminated.

The most useful ICT based on information dissemination technology in Cambodia is:

1. Mobile phone - e.g SMS

2. Mass Media - TV, Radio and Video

3. Tele-center - Extension Hub

4. E-library

5. Internet-websites, social media, ect.

The most needed information for the farmers are:

1. National and international market information

2. Techniques of improvement product.

3. Quality and safety products

4. Weather forecasting

5. Potential product

6. Geographical potential

7. Agriculture service providers

Based on the empirical investigations, farmers have demonstrated strongest demand for the following five agricultural information services: Pest warning and control technology, agricultural price information, planting/farming technical guidance, new product and new agricultural policy.

The most important findings of the empirical investigations is the need to have information and knowledge brokers as an intermediary between information providers and farmers. Therefore, the main information users for piloting the mobile Internet based information dissemination system in the project are be the key farmers in villages and farm commune centres who have sufficient education qualifications and IT skills to understand and absorb 
the information and knowledge. They will then communicate the information and ideas to local farmers as an information and knowledge broker.

The content to be disseminated to farmers should be easy to understand. The field investigation analysis has suggested that farmers would like to see the information being presented using video, audio, image, simple and short text messages. The initial piloting materials can be based on the most popular paper based materials, such as farmers' notes and bulletins. Other potential piloting information would be based on the current available information resources and knowledge repository, such as the selection of the new rice varieties and use of fertilisers because farmers are very keen to adopt the new varieties and technologies to improve the rice productivity.

\section{Adopting Chinese experience and development of AgriApp}

To share the China'success story, thisresearch project introduced China's experience and best practice in disseminating agricultural information to the vast number of farmers using ICTs in the project workshop. The presentation and demonstration in the workshop included Chinese agricultural information service models, latest development, hotline 12316, Hunan Nongxintong SMS, Nonghuibao App, Fujian 3-in-1 integrated service platform, etc. The Cambodian Agricultural representatives were very keen to learn from Chinese advanced agricultural information technology and development models. They strongly believed that conducting the agricultural information service pilot project under the GMS agriculture network platform can help Cambodia to develop the agricultural information services and improve the agricultural productivity.

The project team also conducted live demonstrations to farmers during the field trips to show how farmers in China can access important agricultural information and make online inquires via mobile Internet. Farmers were fascinated by the demonstration although most of them may not be able to benefit from this type of dissemination model directly in the near future due to their low lever education and computer literacy.

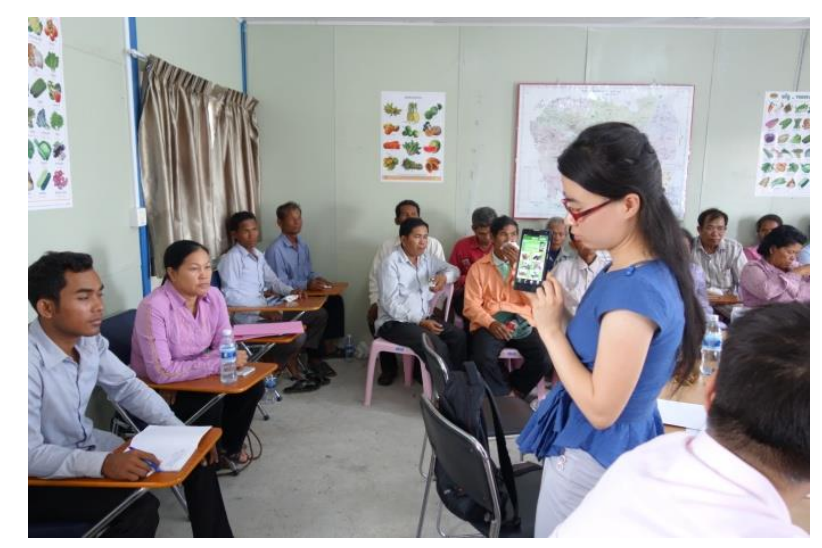

Figure 2. Field demonstration

Based on the field investigations, China's experience, and the technical expertise of the project partners, the dissemination platform and prototype App called AgriApp were developed.The system consists of two parts: the agricultural information database management system in server-side and the agricultural information service application in mobile-side. 
The mobile side is an Android program that currently have three main functions: 1 . Agricultural information dissemination that is designed to show all the agricultural information in different categories; Agricultural information search that allows the users to use the search function to query the information based on their interest and needs; 3 . Agricultural information inquiry that allow the users to submit the problems that they encounter in their farming activities by using text description and images, so the system can provide relevant answer based on its knowledge base and users' location. User questions will be transferred to the server side along with the geographic location information to better help the administrators identify where these farmers are and provide more accurate and effective feedback.

The server side is developed to enable the management of messages from the mobile users (see sample screenshots in figure 3). The administrator also can edit and post his/her own message, such as some useful agricultural info and disaster alerts to the end users through this server application. More importantly, the server program can use a GIS map engine to display the locations of all message senders, thus to help the administrators to better address end users' inquires. This is very useful for future scientific analysis.
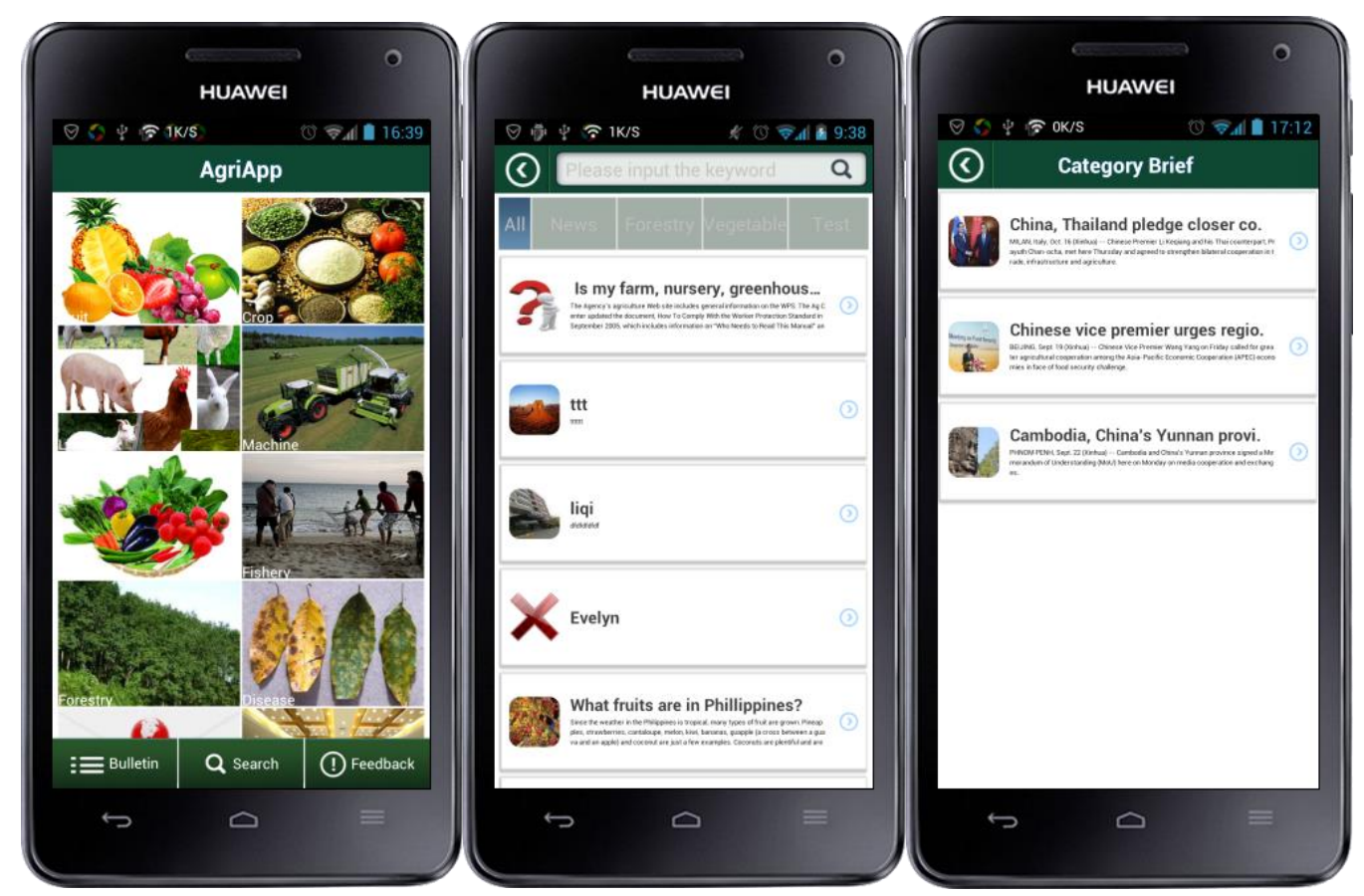

Figure 3.Sample screenshots of AgriApp

The agricultural information database management system provides data management functions to the administrator, such as data entry, data display, data modification, and data deletion (see the sample screenshots in figure 4). It has three main functions: 1. information content management, 2 . user inquiry management, and 3. information display management. While the agricultural information service application provides farmers with three main functions, like agricultural information display, query/question consultation, etc. This type of information platform enables two-way communications of agricultural information between farmers and the information systems including expert team in the background, which forms an effective mechanism among information sharing and dissemination, and achieves sustainable development of the platform. 


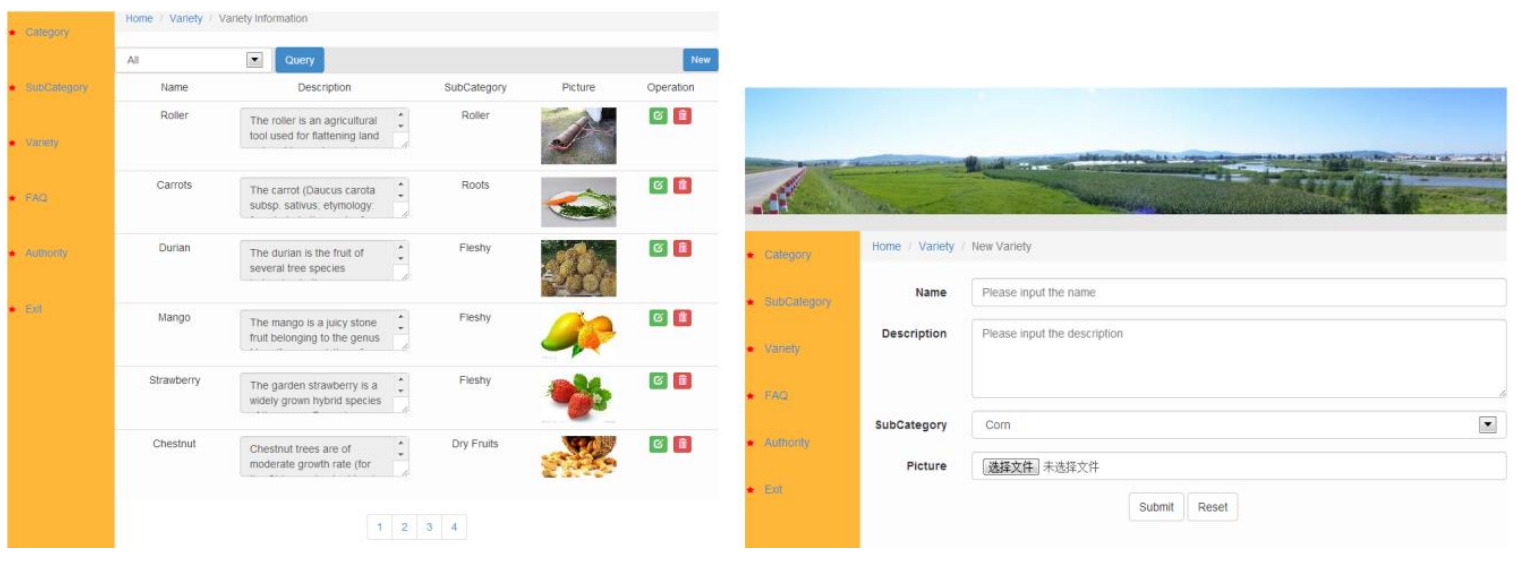

Figure 4. Sample screenshots of AgriApp content management system

The prototype AgriApp was initially tested for its suitability in Cambodia. Project team visited Cambodia for on-site system deployment, training, and promotion. Over 30 Cambodian agricultural officials and farmers were invited to participate in the training. The project team introduced the AgriApp and provided the step-by-step demonstration on the use of theApp to ensure that all participants were fully familiar with its application.

All stakeholders participated in the training workshop discussed the issues on how to effectively promote the system in Cambodia to fully benefit the farmers. The project team invited a number of local farmers to try the App on their phones. The farmers were impressed by the useful functions after going through them with the technical assistance. They showed their interest to continue using the AgriApp to better help their farming activities.

The senior officers in Cambodia governmentalso showed their interest in promoting AgreiApp and pointed out that this new technology represents the future trend for the agricultural information dissemination and has great advantages over traditional dissemination approaches, e.g. call centre, SMS, with regard to the interactivity and costs. They stressed that this new dissemination model should be promoted widely in Cambodia.

\section{Conclusion}

The research reported in this paper aims to improve agricultural information dissemination in Cambodia by adapting China's experience in using Mobile Internet Technologies. To achieve this aim, the research first conducted a comprehensive review on agricultural information service models in China and their suitability for Cambodia. A number of empirical investigations on the current information provision and farmers' information needs and technology adoption intention are examined through surveys, interviews and focus groups. A prototype AgriApp is developed and tested in Cambodia and has received very positive feedback from key stakeholder. The key novelty of AgriAPP is the use of comprehensive knowledge base and the advanced GPS technologies to locate users and to provide tailor made advice suitable to the specific needs of the user. The improved App tools will be developed in the future for wider adoptions.

To improve the agricultural information and knowledge transfer in Cambodia, this research identifies two major issues to be addressed: one is to meet the farmers' urgent needs of information services; and the second is to improve the current ICT infrastructure andthe outdated and ineffective information management and service methods that are not taking 
advantages of emerging ICTs. The mechanisms for developing effective ICT-based information dissemination models should be government-led, centralized services and market-oriented operations. Based on mobile Internet and GIS technology, the comprehensive agricultural information service platform, incorporating voice, network and mobile terminal, is an important direction for Cambodian agricultural information dissemination and mobile service applications. This interactive multi-channel service model can effectively transfer much needed information to farmers so as to improve their skills and productivity. In addition, this service model is also cost effective and needs low system maintenance and facilitate better communications.

It is believed that the experience and findings from this research provide a useful direction for researchers and practitioners in developing future ICT based information processing and dissemination systems and will help other developing countries to learn from China's experience and best practice in their endeavour of applying emerging ICTs in agriculture information dissemination and sharing.

Future research will be carried out to further improve the data sources and functionalities of the AgriApp. More field tests will also be conducted with various users, especially agriculture extentionists, to understand its potential effectiveness and impact.

\section{Acknowledgement}

The work reported in this paper is part of a research project on prompting agricultural knowledge and information flows. The authors would like to acknowledge the financial support provided by the Agricultural Technology Transfer (AgriTT) programme which is funded by UK Department for International Development (DFID). Project partners, Supermap in China, was responsible for design and development ofAgriApp for the project, and, CARDI in Cambodia, provided valuable background information and assisted the Cambodian field investigation and training workshops. The authors are very grateful for their important contributions.

\section{References}

1. CARDI, 2014. "Report on study of current agricultural information dissemination status and development environment in Cambodia". Cambodian Agricultural Research and Development Institute. Report of AgriTT project "Application of Mobile Internet Technology for Agricultural Information Dissemination in Cambodia".

2. EC-FAO food security programme, 2015. "Exchanging Agricultural Market Information through SMS in Cambodia”, FAO Technical Brief, GCP/RAS/247/EC. Accessed on 15 July

2015:http://www.fao.org/fsnforum/sites/default/files/resources/Cambodia\%20SMS\%20T echnical\%20Brief.pdf

3. Gakuru, M., Winters, K. and Stepman, F. 2009, "Innovative Farmer Advisory Services Using ICT, IST-Africa 2009 Conference Proceedings Paul Cunningham and Miriam Cunningham (Eds) IIMC International Information Management Corporation, 2009 ISBN: 978-1-905824-11-3, 06 - 08 May 2009, Uganda.

4. Li, D. 2009. China Rural Informatization Development 2009 Report (in Chinese). Publishing House of Electronics Industry, Beijing.

5. Li, D. 2011. China Rural Informatization Development 2010 Report (in Chinese). Beijing Institute of Technology Press, Beijing. 
6. Liu, X. 2010. Reflections on the development of Agricultural Informatization. In Chinese. In Chinese. Silicon Valley, 1671-7597（2010）1210005-01

7. MOA Information Centre, 2014. Summary of contemporary Chinese approaches of ICTbased agricultural information dissemination. Research Report published by Information Centre, Minister Of Agriculture (MOA), P.R. China

8. Yu, B., \&Diao, X. (2011). Cambodia's agricultural strategy: Future development options for the rice sector. Cambodia Development Resource Institute (CDRI), Council for Agricultural and Rural Development (CARD), and IFPRI Special Report. Phnom Penh, Cambodia: CDRI, 1284(1283), 1282.

9. Zhang, J. 2012. Formation Conditions and Development characteristics of Chinese Agricultural Information Service Model. Chinese Information Industry, 2012, (04).

10. Zhang, Y.; Hu, Y. and Duan, Y. 2015. Supporting Chinese Farmers with ICT-Based Information Services: An Analysis of Service Models. International Conference on EBusiness (ICE-B 2015). Colmar, France, 20-23, July 2015. 